\title{
Workforce quality culture in contemporary economy considerations regarding Romania
}

\author{
Petronela Mateescu - “Al. I. Cuza” University of Iasi, Romania
}

\begin{abstract}
Quality culture development relies on the understanding of the laws of change in force in an institution or organization, and it requires knowledge of the culture evolution in that organization.

The employees of an organization feel whenever certain changes occur and they should therefore be aware that all the organization decision makers must get involved in planning and implementing the changes, so as to assure the former that everything goes according to the plan.
\end{abstract}

\section{Keywords}

workforce, quality culture, workforce quality

JEL Codes: J24, J54, J80

\section{Workforce Quality Culture in Contemporary Economy}

There are numerous quality culture development strategies, depending on the place and workforce employed by the organization. They have been thoroughly studied and debated upon, which finally resulted in awareness raising on the concept of quality culture among all the people involved. This is meant to create a new concept within the organization able to overcome all the discrepancies and disagreements that may have a negative influence on the organization operation.

The following principles have to be complied with in order to achieve high quality:

$>$ quality does not happen by chance, but it is the outcome of a lengthy process;

$>$ quality should be the preoccupation of each employee;

$>$ all the activities should be accurately performed from the very beginning;

$>$ quality is the result of a continuous learning process improvement;

$>$ quality is achieved as a result of a communication and cooperation process.

Employees should be given the opportunity to express their opinions, concerns and fears openly, so as to be able to better understand the need of change and to act according to the expectations of the management.

For an adequate quality culture development process, each employee of an organization should comply with certain compulsory characteristics, which are:

$>$ acceptance of a quality culture philosophy at all the organization levels,

$>$ efficient communication among departments, between departments and management, between employees and management,

$>$ rewarding and recognition of highly deserving employees.

Several qualitative research personalities have talked about the need to implement in any organization, regardless of its size, an adequate quality culture, according to the place, time and types of employees.

One of the most fervent supporters of this concept was J. M. Juran, qualitative research specialist and theoretician, who proposed and implemented the concept of "conflict between 
cultures", that is between those who want change and those who reject it or are opposed to the idea.

The management should take the necessary actions to identify each side or the opposing structures, and then to discuss and explain the reasons accounting for the need of change, which will finally lead to success within the organization.

The organization management should identify, either from the very beginning, or throughout the process, the need of change of the mentality of the workforce related to the most sensitive aspect, which is quality. Senior management should consider this aspect, as the whole organization staff is involved in the provision of services or goods, which will be used or distributed within or outside the organization.

As any other entity, an organization operates according to well-established rules and is composed of staff that sometimes varies, which also impedes upon the quality of the services or goods. There are however people within the organization, both at the management and at the production levels, who behave according to the "it might work" rule or, even more frequently, according to the "to err is human" principle. Conducting the organization business according to these principles may seriously harm both the company image, and profit and turnover. This type of workforce is in a permanent need of control and inspection designed to ascertain the deviations or differences that they should have been able to identify and analyze themselves, and then make the adequate decision related to the solving of the deficiencies found.

Nonobservance of these rules leads to the creation of noncompliant goods, whose sometimes major deficiencies require recovery costs that result into an artificial product or service cost increase, which has a boomerang effect on the organization. If such products or services are launched on the market, they will most certainly trigger a loss of company reputation before its regular or prospective customers.

The organization management should perform an extremely thorough analysis of the main quality policy objectives and they should also develop a simple and useful method to increase the employees' interest in organizational quality and culture. Experts call this quality culture shaping and development method group culture analysis. By means of this analysis method, senior management should identify the groups inside the organization that have the highest involvement in producing and promoting the product or service quality levels.

The analysis should also determine the responsibilities of the departments both directly and indirectly connected to the level of quality of the goods and services provided by the organization. The analysis carried out by the management should establish to what extent there are major differences between the current values and the culture of the inner groups, where they should start from when implementing these measures, which will finally lead to objective fulfillment, that is higher quality levels.

Laying the foundation of these transformations of the organization cultural environment should start from the senior management and work its way down to the last performer in the organization.

Organizational quality culture is therefore the day-to-day manifestation of the workforce within the organization, underlying the employees' values, traditions, behavior and attitude at the workplace.

Quality has ceased to be the sole preoccupation of the organization, as it has become a concern for each individual, thus turning into an education and culture component, which allows a better understanding of its necessity, as well as the discovery of what is best in the world.

Quality is also a behavior component, involving persistence, resumption, review and tenacity in one's work.

Although the notion of quality, as a fundamental component of the human behavior, exists from the beginning of its history, the concept of quality has been tackled by the management science for about two decades, when research was initiated in Europe, and the quality actions materialized within each organization in organizational objectives and structures. 
Organizational management has therefore enriched itself with a new field - that of quality management.

The development of all the workforce management processes, for a coherent personnel administration, requires the following:

- modernization of the initial and continuous workforce training system, for the purpose of providing the required professional skills.

- motivation, psychological assurance and work relations improvement, designed to attain higher staff satisfaction related to their professional expectations and social status requirements, and at the same time meant to achieve a balance between the institution and employee interests.

Workforce management should consider the following priorities:

- international cooperation development and implementation of the European workforce management good practices;

- extended partnerships with the civil society and inner cooperation within the field of practice;

- law observance monitoring in workforce management;

- development of coherent, unified, transparent and non-discriminatory personnel policies and procedures;

- professionalization of the workforce management practices;

- improvement of the workforce career management system;

- correlation between the employees professional careers and their initial and continuous training programs;

- modernization of the institutional structure of staff initial and continuous professional training;

- assurance of a tighter connection between the operative work needs, theoretical professional training and internships in the company initial and continuous training institutions;

- work environment improvement, work safety and security assurance, staff cohesion, motivation and disciplinary practices provision;

- better organizational culture management and implementation of a modern, effective and efficient behavior of the institution workers;

- development of computer-based personnel data management solutions.

Workforce quality is closely connected to and dependent upon both the level of general education and professional training, and the country's economic development.

Throughout the millenniums, man has evolved from plant cultivator and animal breeder, to producer and even creative worker nowadays. This process also involved the progressive evolution from a mostly physical work to an increasingly intellectual effort. Due to production automation, robotization and computerization, the place and role of the human being in economy has changed, turning creative work into the decisive factor of economic life.

A superior professional training level acquires an overwhelming importance in work potential formation and its putting to good use, which means that school, due to its various levels, fields and specialties, plays a decisive role.

At the same time, the scientific and technical developments, the increasingly complex production processes, the rapid depreciation of the amount of knowledge acquired during initial training, point out the imperative needs of professional training improvement in employees. The actual forms of manifestation of this process are numerous and they differ according to profession and specialty, to company needs, to the requirements of the position held, to the employees' interest and promotion possibilities, etc.

The improvement of the qualitative content of the work itself and its fruits brings about objectively longer spare time opportunities throughout a man's life, which is the expression and premise of an increase of the role of the human factor and of the degree of civilization in general. 


\section{Considerations Regarding Romania}

In Romania, the offer of training programs designed to increase workforce flexibility is limited: only $40 \%$ of the companies provide multi-training programs, and less then $23 \%$ retraining programs. The most frequently evoked reason was the fact that the current knowledge level of the employees meets the organization requirements, and therefore companies preferred to recruit already trained personnel instead of consuming their financial resources for personnel training. A significant percentage of $52.0 \%$ of the companies did not provide professional training because of the high costs of employee training. The initial employee professional training process requires certain financial efforts from the companies, materialized in workforce cost expenses regarding the trainees, the trainers and mentors, the location (rent, electricity and water), equipment and charges ${ }^{1}$.

There are still few companies promoting a systematic human resource development approach. Thus, only $44 \%$ of the companies providing professional training actually have a training strategy and only 33\% included this strategy in the overall company development plan. Most of them enjoy limited resources $(40 \%$ of the companies allocated a special training budget and $20 \%$ of them have employees that are actually involved in organizing professional training activities).

An efficient method used to assess the improvement of the knowledge acquired during the training courses by the trainees is the assessment of the course effect by various means.

Training course providing companies assessed the effect of the courses provided using one or several of the following methods: assessment of the level of satisfaction of the trainees at the end of the professional training, testing the acquired knowledge, assessment by the superior or by means of a questionnaire, use of the production improvement measuring indices.

Further to the analysis of the assessment methods, we noticed that the most frequently used methods were those determining the level of satisfaction of the trainees attending the FPC at the end of the training and those in which the assessment was made by the superior or by means of questionnaires. $91.7 \%$ of all the assessing companies preferred these methods.

$86.3 \%$ of the companies that assessed the effect of the courses used tests, while only about $76.6 \%$ of the assessing companies chose the assessment method based on production improvement measuring indices.

The purchase and commissioning of new equipment, machinery, facilities, as well as the reengineering of the processing processes require a particular level of knowledge of the workers, their training and retraining.

\section{Conclusions}

Here are some of the factors generating competitiveness in our globalized world: knowledge, innovation and training. Highly trained workforce considerably contributes to the reduction of the costs incurred for the implementation of new technologies and, at the same time, supports the employees with a poorer training level to be able to use the new technology. Continuous education thus becomes the main component of the work quality increase strategy. Good knowledge and insight are essential for the stimulation of the use of new technologies, of the prevention of work market segmentation generated by the various levels of employee training.

\footnotetext{
${ }^{1}$ Caracteristici ale formării profesionale în întreprinderile din România (Characteristics of Professional Training in Romanian Companies) - Bucharest 2007, p.43
} 


\section{References:}

1. S.Becker - Capitalul uman-O analiză teoretică şi empirică cu referire specială la educație (Human Capital A Theoretical and Empirical Analysis, with Special Reference to Education), Romanian edition published by All Publishing House, Bucharest, 1997

2. Ricardo, D. - Despre principiile economiei politice şi impunerii (On The Principles of Political Economy and Taxation), vol. I, II, Romanian edition published by the Academic Publishing House, Bucharest, 1962

3. Sehnbruch, K., From the Quantity of Employment to the Quality of Employment: An Application of Amartya Sen's Capability Approach to the Chilean Labor Market, $\mathrm{PhD}$ Thesis, Cambridge University, 2003

4. Caracteristici ale formării profesionale în Intreprinderile din România (Characteristics of Professional Training in Romanian Companies), FORPRO- I.N.S.-Bucharest, 2007

5. Anuarul Statistic al României (Statistical Yearbook of Romania), 1990 - 2008

6. http://europa.eu.int/comm/eurostat/Public/datashop/printproduct/ 